\title{
Antropologia social: passado e presente
}

\author{
E. E. EVANS-PRITCHARD \\ Exeter College | Oxford, Reino Unido \\ tradução BEATRIZ PERRONE MOISÉS iD \\ Universidade de São Paulo | São Paulo, SP, Brasil \\ perrone@usp.br
}

DOI 10.11606/issn.2316-9133.v30i2pe191852

\section{[saudações e agradecimentos]}

Decidi discutir hoje ${ }^{1}$ algumas questões amplas - de método. Os consideráveis avanços na antropologia social nos últimos trinta anos e a criação de novos departamentos em várias universidades incitam a refletir sobre o que é essa disciplina e que direção tem tomado - ou deveria tomar - pois a antropologia deixou de ser uma atividade de amadores para tornar-se uma profissão. Os próprios antropólogos têm opiniões diferentes a respeito disso; há basicamente aqueles que a consideram como uma ciência natural e aqueles, como eu, que a consideram como uma das humanidades. Essa divisão, que reflete sentimentos e valores muito diferentes, fica evidente sempre que são debatidos os métodos e objetivos da disciplina. É ainda mais aguda quando se discutem as relações entre a antropologia e a história, e como a consideração dessa difícil questão evidencia ainda mais os problemas, a ela dedicarei grande parte desta conferência. Para perceber como essas questões surgiram, é preciso voltar os olhos para o período da gênese e desenvolvimento inicial da disciplina.

\section{Origens no século XVIII}

Um tema de especialização não pode ser realmente considerado autônomo até ser ensinado em universidades. Nesse sentido, a antropologia é algo muito novo. Em outro sentido, pode-se dizer que ela começou com as mais antigas especulações da humanidade, já que sempre e por toda parte foram propostas teorias sobre a natureza da sociedade humana. Neste sentido, não existe um momento específico em que se possa dizer que a antropologia começou. Existe, no entanto, um ponto além do qual não é proveitoso situar o início de seu desenvolvimento. O período de nascimento de nossa disciplina foi a segunda metade do século XVIII. Ela é filha do Iluminismo e carrega, ao longo de sua história e até hoje, muitas das características de sua origem.

\footnotetext{
${ }^{1}$ Originalmente publicado em 1950 como “Social Anthropology: Past and Present”. The Marett Lecture, 1950. Man, Vol. 50: 118-124.
} 
$\mathrm{Na}$ França, sua linhagem começa com Montesquieu e escritores como D’Alembert, Condorcet, Turgot e os Enciclopedistas de modo geral, chegando a Saint Simon, que foi o primeiro a propor claramente uma ciência da sociedade, e a Comte, inicialmente seu discípulo, que deu a ela o nome de sociologia. Essa corrente do racionalismo filosófico francês marcaria profundamente a antropologia inglesa mais tarde, através dos escritos de Durkheim e seus alunos e de Lévy-Bruhl, herdeiros diretos da tradição saint-simoniana.

Nossos antepassados foram os filósofos morais escoceses, cujos escritos eram típicos do século XVIII: David Hume, Adam Smith, Thomas Reid, Frances Hutcheson, Dugald Steward, Adam Ferguson, Lord Kames e Lord Monboddo. Esses escritores se inspiravam em Bacon, Newton e Locke, e foram também muito influenciados por Descartes. Insistiam que o estudo das sociedades, que consideravam como sistemas naturais ou organismos, tinha de ser empírico, e que por meio do método indutivo seria possível explicá-las em termos de princípios gerais ou leis, do mesmo modo que os fenômenos físicos tinham sido explicados pelos físicos. Também tinha de ser normativo: a lei natural decorre do estudo da natureza humana, que é a mesma em todas as sociedades e todos os tempos. Esses escritores também acreditavam no progresso ilimitado e em leis de progresso. Sendo por toda parte iguais, os homens deveriam avançar por determinados caminhos entre determinados estágios de desenvolvimento, e tais estágios poderiam ser reconstruídos hipoteticamente pelo que Dugald Stewart chamou de história conjectural e o que mais tarde ficou conhecido como método comparativo. Aí estão todos os ingredientes da teoria antropológica do século XIX e até do presente.

Os escritores que mencionei, tanto na França quanto na Inglaterra, eram evidentemente filósofos no sentido de seu tempo, e assim se consideravam. Apesar de falarem muito em empiricismo, baseavam-se mais na introspecção e no raciocínio a priori do que na observação de sociedades reais. De modo geral, usavam fatos para ilustrar ou corroborar teorias oriundas de especulação. Só em meados do século XIX foram realizados estudos sistemáticos de instituições sociais com alguma preocupação de rigor científico. $\mathrm{Na}$ década entre 1861 e 1871, foram publicados livros que consideramos como nossos primeiros clássicos: Ancient Law [Direito antigo] de Maine (1861), Das Mutterrecht [O direito materno] de Bachofen (1861), La Cité Antique [A cidade antiga] de Fustel de Coulanges (1864), Primitive Marriage [Casamento primitivo] de McLennan (1865), Researches into the Early History of Mankind [Pesquisas sobre os começos da história da humanidade] de Tylor (1865) e Systems of Consanguinity [Sistemas de consanguinidade] ${ }^{2}$ de Morgan (1871). Nem todos esses livros lidavam primariamente com sociedades primitivas, embora os que menos se preocupavam com elas, como Ancient Law, lidassem com instituições comparáveis em períodos iniciais do desenvolvimento de sociedades históricas. McLennan e Tylor, neste país, e Morgan, nos Estados Unidos, foram os primeiros a tratar de sociedades primitivas como um tema que poderia em si mesmo merecer a atenção de especialistas sérios.

\footnotetext{
${ }^{2}$ Nota da Tradutora (N.T.]: O título completo da obra é Sistemas de consanguinidade e afinidade na família humana.
} 


\section{A antropologia no século XIX}

Os autores dessa época, assim como os da geração que os antecedeu, se esforçavam por livrar o estudo de instituições sociais de meras especulações. Achavam também que poderiam fazer isso sendo estritamente empíricos e usando rigorosamente o método histórico comparativo. Com este método, eles e seus sucessores escreveram muitos volumes extensos que supostamente mostravam a origem e o desenvolvimento das instituições sociais: o desenvolvimento do casamento monogâmico a partir da promiscuidade, da propriedade a partir do comunismo, do status ao contrato, do nomadismo à indústria, da teologia à ciência positiva, do animismo ao monoteísmo. Por vezes, especialmente quando se tratava de religião, buscavam-se explicações em termos de origens psicológicas tanto quanto em termos de origens históricas.

Esses antropólogos vitorianos eram homens de notável capacidade, com vastos conhecimentos e evidente integridade. Ainda que enfatizassem demasiadamente semelhanças entre costumes e crenças, e não dessem atenção suficiente às diferenças, estavam investigando problemas reais e não imaginários quando tentavam explicar similaridades notáveis em sociedades muito afastadas no tempo e no espaço; e muitos resultados de valor permanente saíram de suas pesquisas. Não obstante, é difícil ler suas construções teóricas hoje sem se irritar, ou sentir-se envergonhado pelo que nos parece autoglorificação. Hoje percebemos que, embora seu uso do método comparativo lhes permitisse separar o geral do específico e assim classificar fenômenos sociais, as explicações que propunham para tais fenômenos não passavam basicamente de escalas hipotéticas de progresso, em cujas pontas eram situadas, de um lado, formas de instituições e crenças da Europa ou dos Estados Unidos no século XIX e, do outro, suas antíteses. A partir disso era elaborada uma série de estágios, para mostrar qual teria sido logicamente a história do desenvolvimento de uma ponta à outra da escala. A única coisa a fazer, então, era vasculhar a literatura etnológica em busca de exemplos para ilustrar cada um dos estágios. É evidente que essas reconstruções não apenas implicam julgamentos morais como têm necessariamente de ser conjecturais; e que de todo modo não se pode compreender - menos ainda explicar - uma instituição em termos de suas origens, sejam elas concebidas como primórdios, causas ou meramente formas mais simples, num sentido lógico. Apesar de toda a sua insistência no empiricismo em estudos de instituições sociais, os antropólogos do século XIX eram pouco menos dialéticos, especulativos e dogmáticos do que os filósofos morais do século anterior, ainda que pelo menos sentissem que tinham de fundamentar suas construções em grandes conjuntos de evidências factuais, uma necessidade que não sentiam os filósofos morais; assim, uma enorme quantidade de pesquisa bibliográfica original foi realizada e vastos repositórios de detalhes etnológicos foram reunidos e sistematicamente organizados, como por exemplo, para mencionar o mais vasto desses repositórios, em The Golden Bough [O ramo de ouro, de Frazer].

Não surpreende que os antropólogos do século passado escrevessem sobre o que consideravam como história, já que todo o conhecimento naquele tempo era radicalmente histórico, e naquele tempo a história ainda era, na Inglaterra, uma arte literária. A abordagem genética, que tinha dado resultados impressionantes na filologia, predominava, 
como fez notar Lord Acton, no direito, na economia, na ciência, na teologia e na filosofia. Verificava-se por toda parte um esforço apaixonado para descobrir as origens de tudo - das espécies, da religião, do direito etc. -, um esforço constante para explicar o próximo pelo distante que, falando da história propriamente, Marc Bloch chama de 'la hantise des origines' [a obsessão pelas origens].

De todo modo, não creio que a real causa de confusão fosse, como geralmente se supõe, o fato de os antropólogos do século XIX acreditarem no progresso e buscarem um método de reconstruir como tinha ocorrido, pois todos tinham plena consciência de que seus esquemas eram hipóteses que afinal não podiam ser devidamente verificadas. A razão da confusão na maior parte de seus escritos deve ser antes buscada no pressuposto que tinham herdado do Iluminismo, de que as sociedades são sistemas naturais ou organismos, que possuem uma orientação necessária de desenvolvimento que pode ser sintetizada em princípios gerais ou leis. Em consequência disso, consistências lógicas eram apresentadas como conexões reais e necessárias, e as classificações tipológicas, como percursos tanto históricos como inevitáveis de desenvolvimento. Percebe-se claramente como uma combinação da noção de lei científica com a noção de progresso leva, na antropologia como na filosofia da história, a estágios rigidamente delimitados, cuja pretensa inevitabilidade lhes confere caráter normativo.

\section{O século XX}

A reação contra a tentativa de explicar instituições sociais em termos de desenvolvimento paralelo, visto idealmente como unilinear, veio no final do século; e embora essa assim chamada antropologia evolucionista tenha sido reformulada e reapresentada nos trabalhos de Westermarck e Hobhouse, acabou perdendo interesse. Tinha parado de estimular pesquisas, de qualquer modo, já que uma vez estabelecidos os estágios de desenvolvimento humano, investigações nessa linha só podiam oferecer uma nada excitante aplicação de rótulos criados em tempos idos. Alguns antropólogos então buscavam, em maior ou menor grau, inspiração na psicologia, que parecia oferecer soluções satisfatórias para muitos de seus problemas sem terem de recorrer à história hipotética. Verificou-se, desde então, que se estava tentando construir sobre areia movediça. Não falarei mais sobre a relação entre psicologia e antropologia nesta conferência, não porque não a considere importante, mas porque isso exigiria mais tempo do que o de que disponho e também mais conhecimento em psicologia do que possuo para ser devidamente tratado.

Além de ser implicitamente criticada ao desconsiderada por autores como Marett ${ }^{3}$, que buscavam explicações psicológicas para costumes e crenças, a teoria evolucionista foi atacada por duas frentes, a difusionista e a funcionalista. A crítica difusionista se baseava no fato bastante óbvio de que a cultura é muitas vezes emprestada, e não emerge de desenvolvimento espontâneo de certas potencialidades sociais e de uma natureza humana compartilhadas. Suposições contrárias e discussões sobre mudança social sem referência a

\footnotetext{
${ }^{3}$ [N.T.]: Robert R. Marett (1866-1943), antropólogo homenageado pelo ciclo de conferências de que esta faz parte, era especialista no estudo das religiões.
} 
fatos equivalem a cair no escolasticismo cartesiano. Essa abordagem teve, infelizmente, uma influência pouco duradoura na Inglaterra, certamente em parte devido a seu uso acrítico por Elliot Smith, Perry e Rivers. A outra forma de ataque, a funcionalista, tem tido muito mais influência, e é muito mais radical. Condena igualmente a antropologia evolucionista e a difusionista, não somente pelo fato de suas reconstruções históricas não serem passíveis de verificação, mas também simplesmente porque ambas são abordagens históricas - na visão de autores funcionalistas, a história de uma sociedade é irrelevante para seu estudo como sistema natural.

O mesmo tipo de movimento ocorria simultaneamente em outros campos do conhecimento. Havia biologia funcional, direito funcional, economia funcional, e assim por diante. Esse ponto de vista foi mais facilmente acatado por muitos antropólogos sociais porque os antropólogos em geral estudam sociedades cuja história não pode ser conhecida. Sua rápida aceitação também se deveu em parte à influência vinda do outro lado do Canal da Mancha, do racionalismo filosófico de Durkheim e sua escola. Essa influência teve, em termos gerais, um efeito não só profundo como benéfico sobre a antropologia inglesa. Injetou uma tradição preocupada com grandes questões gerais na tradição inglesa, mais empírica e fragmentada, exemplificada pelo modo como escritores teóricos como Tylor e Frazer usaram seu material, incluindo muitos relatos de primeira mão a respeito de povos primitivos, escritos por viajantes, missionários e administradores e as primeiras investigações sociais neste país. Por outro lado, estudiosos que não se ancoram firmemente num vasto cabedal de fatos etnográficos podem facilmente ser levados a discussões etéreas sobre palavras, a classificações áridas, à pretensão ou ao completo ceticismo.

\section{A teoria funcionalista}

A teoria funcionalista ou organicista da sociedade que hoje reina na antropologia social inglesa não é nova. Como vimos, foi defendida de vários modos por antropólogos do século XIX e pelos filósofos morais antes deles, e tem um pedigree muito mais longo na filosofia política. Em sua forma mais moderna e mais mecanicista, foi longamente apresentada por Durkheim e, especialmente referida à evolução social, por Herbert Spencer. Mais recentemente, foi proposta de modo mais claro e consistente por Radcliffe-Brown: as sociedades humanas são sistemas naturais cujas partes são todas interdependentes, cada uma delas servindo, num complexo de relações necessárias, para manter o todo. O objetivo da antropologia social é sintetizar toda a vida social em leis ou afirmações gerais acerca da natureza da sociedade, que permitam previsão. O que é novo nessa reapresentação da teoria é a insistência em que uma sociedade pode ser satisfatoriamente compreendida sem referência a seu passado. Praticamente todos os filósofos morais do século XVIII apresentavam sua concepção dos sistemas sociais e leis sociológicas na forma de uma história em grande estilo - uma história natural das sociedades humanas. E, como vimos, a paixão persistente de seus sucessores vitorianos era a busca das origens de que se tinham desenvolvido todas as instituições, pela operação das leis do progresso. A versão moderna do estudo naturalista das sociedades, ainda que se mencione às vezes, como que por obrigação, a possibilidade do estudo de mudança social, defende que a compreensão do 
funcionamento de uma sociedade não requer que o estudioso saiba nada de sua história, do mesmo modo que um fisiologista não precisa conhecer a história de um organismo para compreendê-lo. Ambos são sistemas naturais, e podem ser descritos em termos de leis naturais, sem recurso à história.

Em grande parte graças à orientação funcionalista, com sua insistência na interrelação entre coisas, foram realizados estudos de campo abrangentes e minuciosos na antropologia moderna, de um tipo completamente desconhecido por antropólogos do século XIX, que se contentavam em deixar que leigos coletassem os fatos em que baseavam suas teorias. Também graças a ela, os antropólogos de hoje percebem com mais clareza do que seus predecessores que só se pode chegar a uma compreensão do comportamento humano considerando-o em seu contexto social amplo. Todos os antropólogos aceitam atualmente que todas as atividades de sociedades primitivas devem ser estudadas sistematicamente em campo, e todos possuem a mesma abordagem holística quando registram e interpretam suas observações.

Contudo, uma teoria pode ter valor heurístico sem ser sólida, e há muitas objeções à teoria funcionalista, que afinal se reduz ao pressuposto de que as sociedades humanas são sistemas do tipo que se afirma que são. No caso de Malinowski, a teoria funcionalista, apesar da ampla defesa que ele fez dela, na prática não passava de um recurso literário. Além disso, a teoria pressupõe que, em determinadas circunstâncias, nenhuma parte da vida social pode ser diferente do que é e que todo costume possui valor social, acrescentando assim a um determinismo ingênuo uma teleologia e um pragmatismo rudimentares. É fácil definir o objetivo da antropologia social como sendo o estabelecimento de leis sociológicas, mas nada que se pareça remotamente com uma lei das ciências naturais foi proposto até agora. As afirmações gerais que foram feitas costumam ser especulativas e, de todo modo, demasiado gerais para terem algum valor. São muitas vezes pouco mais do que conjecturas baseadas no senso comum ou a posteriori, que por vezes degeneram em meras tautologias ou obviedades. Além disso, é difícil reconciliar a afirmação de que uma sociedade veio a ser o que é através de uma sucessão de eventos particulares com a afirmação de que pode ser descrita de modo abrangente em termos de lei natural. Em sua forma extrema, o determinismo funcionalista leva ao relativismo absoluto e não faz sentido, nem para a teoria em si nem para qualquer pensamento.

Embora por essas e outras razões eu não possa aceitar, sem muitas ressalvas, a teoria funcionalista atualmente dominante na antropologia inglesa, não afirmo, como verão, que sociedades são ininteligíveis ou que não são sistemas, em algum sentido. Objeto ao que me parece continuar sendo a mesma filosofia doutrinária do Iluminismo e dos antropólogos criadores de estágios do século XIX, agora com o conceito de progresso no lugar do de evolução. Suas construções permanecem sendo postuladas e impostas aos fatos. Atribuo isso ao fato de os antropólogos terem sempre tentado tomar como modelo as ciências naturais, em vez de as ciências históricas, e é para esse ponto importante que passo em seguida. Peço desculpas aos historiadores se o que disser a respeito lhes parecer óbvio. Minhas observações seriam acaloradamente discutidas pela maioria de meus colegas antropólogos na Inglaterra. 


\section{Antropologia e história}

Para que uma discussão das relações entre história e antropologia social seja útil, é necessário notar que várias perguntas diferentes estão sendo colocadas. A primeira é se o conhecimento de como um sistema social específico veio a ser o que é auxilia a compreender sua constituição atual. Nesse ponto, é preciso distinguir dois sentidos de história, embora a distinção seja menos fácil de manter em sociedades letradas do que nas não-letradas. No primeiro sentido, história é parte da tradição consciente de um povo e operante em sua vida social. É a representação coletiva dos fatos, distinta dos fatos em si. Isso é o que antropólogos sociais chamam de mito. Os antropólogos funcionalistas consideram que a história nesse sentido, em geral uma mistura de fato e imaginação, é altamente relevante para o estudo da sociedade de que faz parte.

Por outro lado, rejeitaram completamente a reconstrução das circunstâncias da história de povos primitivos das quais não existem, ou existem poucos, documentos ou monumentos. Pode-se argumentar em favor dessa rejeição, embora, a meu ver, não com a segurança com que se costuma fazê-lo, pois toda história é necessariamente uma reconstrução, sendo o grau de probabilidade de cada reconstrução dependente das evidências disponíveis. O fato de os antropólogos do século XIX serem acríticos em suas reconstruções não deveria levar à conclusão de que qualquer esforço nesse sentido seja perda de tempo.

Com a água de banho da história presumida os funcionalistas jogaram fora também o bebê da história válida. Dizem - Malinowski vocifera - que mesmo quando há registros da história de uma sociedade, ela é irrelevante para seu estudo funcional. Considero essa posição inaceitável. A afirmação de que se pode entender o funcionamento de instituições num determinado momento sem saber como vieram a ser o que são ou o que viriam a ser me parece absurda. Além disso, a meu ver, negligenciar a história das instituições impede antropólogos funcionalistas não só de estudar questões diacrônicas como também de testar as próprias construções funcionais que mais valoriza, pois é precisamente a história que lhes fornece uma situação experimental.

O problema que levanto aqui está-se tornando premente, porque antropólogos estão hoje estudando comunidades que, embora bastante simples na estrutura, estão incluídas em, e fazem parte de, grandes sociedades históricas, como as comunidades rurais irlandesas e indianas, as tribos beduínas ou as minorias étnicas nos Estados Unidos e em outras partes do mundo. Não podem continuar ignorando a história, fazendo da necessidade virtude, e devem explicitamente admitir ou rejeitar sua relevância. À medida que antropólogos voltam sua atenção para comunidades civilizadas mais complexas, essa questão torna-se mais aguda e a direção do desenvolvimento teórico da disciplina dependerá largamente das respostas que forem dadas a ela.

Uma segunda questão é de outro tipo. Hoje nos perguntamos, não se ao estudar uma sociedade particular sua história deve ser incluída no estudo, mas se ao realizar estudos sociológicos comparativos, de instituições políticas ou religiosas por exemplo, deveríamos incluir sociedades que nos são apresentadas por historiadores. Apesar de afirmarem que a antropologia social tem o objetivo de se tornar uma história natural das sociedades humanas, isto é, de todas as sociedades humanas, os antropólogos funcionalistas, pelo menos na 
Inglaterra, em sua aversão geral pelo método histórico, têm praticamente ignorado escritos históricos. Ao fazê-lo, negaram a si mesmos, em seus estudos comparativos, o acesso ao valioso material oferecido por sociedades históricas estruturalmente comparáveis a várias sociedades bárbaras contemporâneas que consideram como sua província.

A terceira questão, para mim a mais importante, é metodológica: a antropologia social, com sua atual desconsideração pela história, não seria ela mesma um tipo de historiografia? Para responder a essa pergunta, temos de começar por observar o que o antropólogo faz. Vai viver por alguns meses ou anos com povos primitivos. Vive tão próximo deles quanto possível, aprende a falar sua língua, a pensar com seus conceitos e a sentir seus valores. Depois revive essas experiências de modo crítico e interpretativo, nas categorias conceituais e valores de sua própria cultura e nos termos do conjunto de conhecimentos de sua disciplina. Em outras palavras, traduz de uma cultura para outra.

Nesse nível, a antropologia social é uma arte literária e impressionista. Mas mesmo num estudo etnográfico específico o antropólogo tenta fazer mais do que compreender o pensamento e os valores de um povo primitivo e traduzi-los para sua própria cultura. Também procura descobrir a ordem estrutural da sociedade, os padrões que, uma vez localizados, lhe permitem vê-la como um todo, como um conjunto de abstrações interrelacionadas. Assim, a sociedade se torna não somente inteligível tal como é, no nível da consciência e da ação, mas também sociologicamente inteligível.

Historiadores, pelo menos historiadores sociais e talvez mais particularmente historiadores econômicos entenderão, creio, o que quero dizer com "socialmente inteligível". Afinal, a sociedade inglesa do século XI era entendida por Vinogradoff de modo bem diferente daquele de um normando ou anglo-saxão ou estrangeiro que tivesse aprendido as línguas nativas e vivesse a vida dos nativos. Do mesmo modo, um antropólogo descobre na sociedade nativa algo que nenhum nativo poderia lhe explicar e que nenhum leigo, por mais que participe daquela cultura, pode perceber - sua estrutura de base. Essa estrutura não pode ser vista. É um conjunto de abstrações e cada uma delas, embora derivadas da análise de comportamento observado, é fundamentalmente uma construção do próprio antropólogo. Relacionando essas abstrações umas às outras logicamente, de modo a apresentarem um padrão, ele pode ver a sociedade naquilo que é essencial e como um todo.

O que estou tentando dizer talvez seja mais bem ilustrado pelo exemplo da língua. Um nativo entende sua língua e um estrangeiro pode aprendê-la. Mas certamente nem o nativo nem o estrangeiro pode dizer quais são seus sistemas fonológico e gramatical. Estes só podem ser descobertos por um linguista treinado, cuja análise lhe permite reduzir a complexidade da língua a certas abstrações, e mostrar como tais abstrações estão interrelacionadas num sistema ou padrão lógico. Isso é o que o antropólogo social também procura fazer: procura revelar os padrões estruturais de uma sociedade. Tendo isolado tais padrões numa sociedade, compara-os com padrões em outras sociedades. O estudo de cada nova sociedade alarga seu conhecimento da gama de estruturas sociais básicas e lhe dá melhores condições para construir uma tipologia de formas, determinar suas características essenciais e as razões de suas variações. 
Tentei mostrar que o trabalho do antropólogo social se realiza em três principais fases ou, dito de outro modo, em três níveis de abstração. Primeiro ele busca entender as características manifestas significantes de uma cultura e traduzi-las nos termos de sua própria cultura. Isso é precisamente o que faz um historiador. Não há nesse plano nenhuma diferença fundamental de objetivo ou método entre as duas disciplinas e ambas são igualmente seletivas no uso de seus materiais. A semelhança entre elas foi obscurecida pelo fato de o antropólogo social fazer um estudo direto da vida social, ao passo que o historiador faz um estudo indireto, através de documentos e outras evidências remanescentes. É uma diferença técnica, não metodológica. A historicidade da antropologia também foi obscurecida por sua preocupação com sociedades primitivas que não possuem registro histórico. Mas, novamente, essa não é uma diferença metodológica. Concordo com Kroeber que a característica fundamental do método histórico não é a relação cronológica entre os eventos, mas sua integração descritiva; e essa característica a historiografia compartilha com a antropologia social. O que os antropólogos sociais têm fundamentalmente feito é escrever segmentos de história, descrições integradas de povos primitivos num dado momento, que em outros aspectos são como as descrições de historiadores ao longo de um certo período, pois o historiador não registra sequências de eventos apenas, mas busca estabelecer conexões entre eles. A determinação dos antropólogos em ver cada instituição como parte funcional de um todo social tampouco faz diferença do ponto de vista metodológico. Se me permitem fazer uma avaliação, qualquer historiador moderno tem como meta o mesmo tipo de síntese.

De modo que, a meu ver, o fato de as questões dos antropólogos serem geralmente sincrônicas enquanto as dos historiadores costumam ser diacrônicas é uma diferença de ênfase nas condições específicas e não uma divergência de interesses. Quando o historiador concentra sua atenção exclusivamente numa cultura particular e num determinado período da história, escreve o que chamaríamos de monografia etnográfica (Culture of the Renaissance [Cultura do Renascimento], de Burckhardt, é um exemplo notável). Quando, por outro lado, um antropólogo social escreve sobre o desenvolvimento de uma sociedade ao longo do tempo, escreve um livro de história - diferente, é verdade, da narrativa costumeira e da história política, mas essencialmente igual à da história social. $\mathrm{Na}$ falta de outro exemplo, devo citar meu próprio The Sanusi of Cyrenaica [Os Sanusi da Cirenaica].

Na segunda fase de seu trabalho, o antropólogo social dá um passo além e busca, pela análise, revelar a forma latente subjacente de uma sociedade ou cultura. Ao fazê-lo, vai além dos historiadores mais temerosos e conservadores, mas muitos historiadores fazem o mesmo. Não estou pensando em filósofos da história, como Vico, Hegel, Marx, Spengler e Toynbee, nem naqueles que podem ser caracterizados como historiadores sociais ou autores da escola Kulturgeschichte, como Max Weber, Tawney e Sombart, ou Adam Smith, Savigny e Buckle, mas em historiadores no sentido mais estrito e ortodoxo, como Fustel de Coulanges, Vinogradoff, Pirenne, Maitland ou Powicke. Pode não fazer a menor diferença que os escritos históricos que nós antropólogos consideramos como exemplos de método sociológico geralmente considerem períodos iniciais da história, em que as sociedades descritas são mais semelhantes a sociedades primitivas do que as sociedades complexas de períodos posteriores, e para as quais os documentos históricos não são numerosos demais 
para serem abarcados e assimilados por uma única mente, do mesmo modo que culturas primitivas. Quando lemos os trabalhos desses historiadores, sentimos que estão estudando as mesmas coisas do mesmo modo e que buscam atingir o mesmo tipo de compreensão de tais coisas.

$\mathrm{Na}$ terceira fase de seu trabalho, os antropólogos comparam as estruturas sociais reveladas por suas análises numa vasta gama de sociedades. Quando um historiador almeja fazer um estudo similar em seu próprio campo, é chamado de filósofo. Mas penso que não é verdade, como se costuma dizer, que a história é um estudo do particular e a antropologia social um estudo do geral. Em certos estudos históricos, a comparação e a classificação são bastante explícitas; sempre estão implícitas, pois a história não pode ser escrita a não ser a partir de algum tipo de parâmetro, por comparação com a cultura de um outro tempo ou povo, ainda que seja apenas a do próprio autor.

Concluo, portanto, acompanhando Kroeber, que apesar de obviamente existirem muitas diferenças entre a antropologia social e a historiografia, trata-se de diferenças nas técnicas, nas ênfases e nas perspectivas, mas não diferenças de método e de objetivo. Creio ainda que uma compreensão mais clara de que é assim levará a uma conexão mais próxima entre estudos históricos e antropológicos do que a atualmente proporcionada por encontros pontuais de etnologia e arqueologia pré-histórica, e que isso vai beneficiar muito ambas as disciplinas. Historiadores podem fornecer a antropólogos sociais um material valiosíssimo, selecionado e garantido por técnicas críticas de teste e interpretação. Antropólogos sociais podem fornecer a historiadores do futuro algumas de suas melhores fontes, baseadas em observação cuidadosa e detalhada, e podem, por sua descoberta de formas estruturais latentes, lançar sobre a história a luz dos universais. $\mathrm{O}$ valor de cada uma das disciplinas para a outra será reconhecido, creio, quando os antropólogos começarem a se dedicar mais a estudos históricos e mostrarem como o conhecimento da antropologia pode iluminar questões históricas.

\section{A antropologia social como uma das humanidades}

A tese que lhes apresentei, de que a antropologia social é um tipo de historiografia e, portanto, em última análise, uma filosofia ou arte, implica que ela estuda sociedades como sistemas morais, e não sistemas naturais, que está mais interessada em esquemas do que em processos, e que por conseguinte busca padrões e não leis científicas, e mais interpreta do que explica. Essas diferenças são conceituais, não meramente de vocabulário. Os conceitos de sistema e lei natural, modelados com base nas teorias das ciências naturais, dominaram a antropologia desde seus primórdios, e quando olhamos retrospectivamente para seus caminhos de desenvolvimento, creio que podemos ver que foram responsáveis por um falso escolasticismo, que levou a formulações rígidas e ambiciosas em série. Uma vez considerada como um tipo específico de historiografia, isto é, uma das humanidades, a antropologia social é liberada desses dogmas essencialmente filosóficos e terá a oportunidade - por mais paradoxal que pareça dizer isso - de ser realmente empírica e, no verdadeiro sentido do termo, científica. Suponho que isso é o que tinha em mente Maitland, quando disse que "a antropologia terá de escolher entre tornar-se história ou nada”. 
Percebi que, tanto na Inglaterra quanto nos Estados Unidos, os estudantes costumam ficar perturbados com essas implicações. Não precisam ficar, porque considerar a antropologia social como um tipo especial de historiografia não significa que suas pesquisas e teorias sejam menos sistemáticas. Assim, quando me perguntam como acho que a antropologia social deveria proceder no futuro, respondo que deve proceder basicamente do mesmo modo que a história social ou a história das instituições, diferentemente da história puramente narrativa e política. Por exemplo, quando um historiador social busca entender as instituições feudais, começa por estudá-las num país da Europa e saber tudo o que pode sobre elas ali. Então as estuda em outras sociedades europeias, para descobrir quais características eram comuns à civilização europeia naquele tempo e quais eram variações locais, tentando perceber cada forma particular como variação de um padrão geral e explicar as variações. Não busca leis, mas sim padrões significativos.

O que mais fazemos, podemos fazer ou deveríamos querer fazer em antropologia social? Estudamos a feitiçaria ou um sistema de parentesco numa sociedade primitiva específica. Se quisermos saber mais sobre esses fenômenos sociais, iremos estudá-los numa segunda sociedade, e então numa terceira, e assim por diante. Conforme aumenta nosso conhecimento e novas questões surgem, cada estudo atinge um nível mais profundo de investigação e nos ensina as características essenciais daquilo que estamos investigando, de modo que estudos particulares ganham um novo sentido e perspectiva. Isso sempre ocorrerá se for respeitada uma condição necessária: que as conclusões de cada estudo sejam claramente formuladas, de tal modo que não apenas testem as conclusões de estudos anteriores como proponham novas hipóteses que possam ser desmembradas em problemas para a pesquisa de campo.

Entretanto, não me parece que o desconforto resida nesse plano, pois deve ser evidente para todo estudante que pensou no assunto que aqueles que mais insistiram em que a antropologia social deveria tomar como modelo as ciências naturais não fizeram pesquisas melhores do que os que adotam o ponto de vista oposto, nem pesquisas de um tipo diferente. Deve-se, antes, ao sentimento de que qualquer disciplina que não tenha por objetivo a formulação de leis e, portanto, a previsão e o planejamento, não vale a dedicação de uma vida toda. Esse elemento normativo na antropologia, como vimos, assim como os conceitos de lei natural e progresso de que deriva, é parte de nossa herança filosófica. Em tempos recentes, a abordagem do tipo ciência natural tem enfatizado a aplicação de suas descobertas, na Inglaterra sobretudo a problemas coloniais e, nos Estados Unidos, a problemas políticos e industriais. Seus defensores mais cautelosos têm afirmado que só poderá existir uma antropologia aplicada quando nossa ciência estiver bem mais avançada do que está hoje, mas os menos cautelosos têm defendido ardentemente a aplicação imediata do conhecimento antropológico no planejamento social; tanto os menos quanto os mais cautelosos justificam a antropologia com base na utilidade. Nem preciso dizer que não compartilho de seu entusiasmo e considero ingênua a atitude de que emerge. Levaria muito tempo fazer uma discussão aprofundada disso, mas não resisto à observação de que, como a história da 
antropologia mostra, o positivismo leva facilmente a uma ética desviada, a um humanismo científico anêmico ou - em casos como o de Saint Simon e Comte - a um Ersatz ${ }^{4}$ de religião.

Concluo resumindo brevemente o argumento que tentei desenvolver nesta conferência e afirmando o que acho que pode ser o caminho da antropologia social no futuro. Os antropólogos sociais, consciente ou inconscientemente dominados, desde os primórdios de sua disciplina, pela filosofia positivista, têm buscado, explícita ou implicitamente, e em geral ainda buscam - pois é isso que resulta - provar que o homem é um autômato e descobrir as leis sociológicas em termos das quais se pode explicar seus atos, ideias e crenças, que à luz disso poderão ser planejadas e controladas. Essa abordagem supõe que sociedades humanas são sistemas naturais e podem ser reduzidas a variáveis. Assim, antropólogos tomaram uma ou outra das ciências naturais por modelo e viraram as costas para a história, que vê os homens de modo diferente e, à luz da experiência, afasta-se de formulações rígidas de qualquer tipo.

Existe, no entanto, uma tradição mais antiga do que a do Iluminismo, com uma abordagem diferente do estudo das sociedades humanas, na qual são vistas como sistemas apenas porque a vida social tem de ter algum tipo de padrão, na medida em que o homem, sendo criatura racional, tem de viver num mundo em que suas relações com quem está à sua volta são ordenadas e inteligíveis. Claro está que penso que os que têm essa visão possuem um melhor entendimento da realidade social do que os outros, mas seja como for, estão-se tornando mais numerosos e isso provavelmente continuará, porque a vasta maioria dos estudantes de antropologia hoje foram formados em alguma das humanidades e não, como acontecia há três décadas, em alguma das ciências naturais. Assim sendo, tenho a expectativa de que no futuro ocorrerá uma virada em direção às disciplinas humanísticas, especialmente em direção à história, e particularmente a história social ou história das instituições, culturas e ideias. Nessa mudança de orientação, a antropologia social irá manter sua individualidade, pois tem questões, técnicas e tradições próprias. Embora provavelmente ainda continue devotando sua atenção por algum tempo a sociedades primitivas, acredito que nessa segunda metade do século passe a dar muito mais atenção do que no passado a culturas mais complexas, e especialmente às civilizações do oriente, extremo e próximo, tornando-se num sentido amplo uma contraparte dos estudos orientais, na medida em que estes são concebidos primariamente como linguísticos e literários - ou seja, encampará as culturas e sociedades, passadas e presentes, dos povos não-europeus de todo o mundo.

\section{Referências bibliográficas}

BACHOFEN, Johann Jakob. 2012 [1861]. Das Mutterrecht. Berlim: GRIN Publishing. COULANGES, Fustel. 2019 [1864]. La Cité Antique. Paris: Prodinnova.

EVANS-PRITCHARD, E. E. 1949. The Sanusi of Cyrenaica. Oxford, Clarendon Press

FAZER, James. 2009 [1890]. The Golden Bough: A Study in Comparative Religion. Oxoford: Oxford University Press.

\footnotetext{
${ }^{4}$ [N.T.]: substituto
} 
MCLENNAN, John Ferguson. 1865. Primitive Marriage: an Inquiry into the Origin of the Form of Capture in Marriage Ceremonies. Edinburgh: A. and C. Black.

MAINE, Henrii. 2017 [1861]. Ancient Law. London: Createspace.

MORGAN, Henry. 1871. Systems of Consanguinity and Affinity of the Family. Washington. Smithsonian Institution

TAYLOR, Edward. 2010 [1865]. Researches into the Early History of Mankind. New York: Oakes Press.

sobre o autor

\section{sobre a tradutora}

\section{E. E. Evans-Pritchard}

Antropólogo britânico, foi professor sociologia africana e antropologia na Universidade de Oxford.

\section{Beatriz Perrone-Moisés}

É professora associada do Departamento de Antropologia da Universidade de São Paulo.

Contribuição de Autoria: Não se Aplica

Financiamento: A produção deste artigo não contou com financiamento à pesquisa.

Recebido em 05/10/2021

Aceito para publicação em 08/12/2021 